\title{
Identification of point mutations in Turkish DMD/BMD families using multiplex-single stranded conformation analysis (SSCA)
}

\author{
Serpil Eraslan ${ }^{1}$, Hülya Kayserili², Memnune Yüksel Apak² and Betül Kirdar ${ }^{3}$ \\ ${ }^{1}$ Division of Molecular Genetics, Düzen Laboratories, Istanbul \\ ${ }^{2}$ Division of Medical Genetics, Institute of Child Health, Istanbul University \\ ${ }^{3}$ Department of Chemical Engineering, Boğaziçi University, Istanbul, Turkey
}

\begin{abstract}
Small mutations are the cause of the disease in one third of cases of Duchenne and Becker muscular dystrophy (DMD/BMD). The identification of point mutations in the dystrophin gene is considered to be very important, because it may provide new insights into the function of dystrophin and direct information for genetic counselling. In this study, we have screened 18 deletion-prone exons (25.5\% of the coding region) of the dystrophin gene by using a modified non-isotopic multiplex single-stranded conformation analysis (SSCA). Mutations responsible for the disease phenotype could be identified in five out of 56 unrelated DMD/ BMD patients without detectable deletions. Two of these mutations, 980-981delCC and 719G > C, are novel mutations which have not been described previously. Four of the five mutations, including 980-981delCC detected in this study are found to be nonsense or frameshift mutations leading to the synthesis of a truncated dystrophin protein. The missense mutation, 719G > C, causing the substitution of highly conserved alanine residue at 171 with proline in the actin binding domain of the dystrophin, is associated with a BMD phenotype. This study also revealed the presence of six polymorphisms in Turkish DMD/BMD patients.
\end{abstract}

Keywords: DMD/BMD; point mutations; multiplex single-stranded conformation analysis (SSCA); nonsense mutation; missense mutation

\section{Introduction}

Duchenne, and its milder allelic form Becker, muscular dystrophy (DMD/BMD) are X-linked recessive neuromuscular disorders resulting from mutations in the gene encoding the muscle protein, dystrophin. ${ }^{1}$

The underlying defects in DMD/BMD are partial deletions in approximately $50-60 \%$ of all DMD and

Correspondence: Betül Kirdar, Boğaziçi University, Department of Chemical Engineering, 80815 Bebek, Istanbul, Turkey. Tel: 90212263 15 40/Ext: 2126; Fax: 9021228724 60; E-mail: kirdar@boun.edu.tr

Received 10 November 1998; revised 21 April 1999; accepted 10 May 1999
$85 \%$ of BMD cases. ${ }^{1}$ These deletions, clustered in the central and near the $5^{\prime}$ end of the dystrophin gene can easily be detected by two separate multiplex gene amplification systems. ${ }^{2,3}$ A small proportion of mutations $(6 \%)$ are duplications. ${ }^{4}$

Small mutations, including point mutations or microdeletions/insertions, are the cause of the disease in the remaining $\mathrm{DMD} / \mathrm{BMD}$ cases, therefore it is very important to find the underlying defect in these group of patients. 203 different mutations have been identified and reported to the Muscular Dystrophy (Point) Mutation Database so far. ${ }^{5}$ Most of these mutations were found to be unique to a patient and no hot spot region could be identified. 
The majority of DMD small mutations are nonsense mutations resulting in the premature termination of translation, giving rise to unstable dystrophins leading to severe DMD phenotype. Mutations causing the mild BMD phenotype may maintain the translational reading frame and result in the synthesis of either correctly localised dystrophin protein with slightly altered function or normal protein at reduced levels. The determination of point mutations within this gene represents a challenge due to its large size and complexity. Since 1991, when the first nonsense mutation in the dystrophin gene was reported by Bulmann et $a l^{6}$ using western blot analysis and direct sequencing, a great effort has been put forward to develop techniques that will enable the systematic identification of point mutations. $^{7-10}$

Single-stranded conformation analysis (SSCA) technique is one of the most commonly used approaches for the screening of the point mutations and/or polymorphisms in the gene of interest. Single or multiplex PCR products corresponding to the various exons of the dystrophin gene including exon-intron boundaries were analysed on long non-denaturing gels by SSCA technique and resulted in the identification of point mutations within this gene. ${ }^{11-13}$

In the framework of this study, we have screened 18 deletion-prone exons of the dystrophin gene by using a modified non-isotopic multiplex SSCA. We have identified five different pathogenic mutations, two of which are novel, and six polymorphisms in 56 nondeletion DMD/BMD patients.

\section{Methods}

\section{Patients}

56 unrelated DMD/BMD patients who did not have any detectable deletions were selected for the screening of point mutations by SSCA analyses. Normal males were included in the study as controls.

\section{PCR Conditions}

Each patient was screened for 18 exonic regions of the dystrophin gene using primers described for multiplex gene amplification systems. ${ }^{2,3}$ Exons 3, 4, 6, 8, 12, 13, 17, 19, 43, 44, $47,50,51,52$ and 60 were amplified either as triplex $(\mathrm{A}-\mathrm{C})$ or duplex sets (D-F) for each patient. Exons to be analysed together on a single SSCA gel were carefully selected according to their size and the location of their singlestranded patterns on the selected gel system. The promoter region (Pm), exon 45 and 48 (G-I) were amplified separately due to their large size (Table 1). Amplifications were performed as described previously. ${ }^{2,3}$ A $1-2 \mu l$ aliquot of each PCR mix was mixed with $5 \mu$ of $98 \%$ formamide, $10 \mathrm{~mm}$ $\mathrm{NaOH}$ and $0.05 \% \mathrm{BPB}$ and $\mathrm{XC}$ dyes. The samples were denatured at $85^{\circ} \mathrm{C}$ for $5 \mathrm{~min}$ and cooled on ice prior to loading on to the SSCA gels.

\section{SSCA for Screening}

Electrophoresis was performed using DGGE apparatus (DGGE-2000, CBS Scientific Company Inc, USA) with a constant circulation of buffer between lower and upper chambers. Optimum electrophoresis conditions for each set (A-I) used for the screening of the small mutations within the dystrophin gene were determined carefully and are summarised in Table 1. The $\mathrm{C} \%$ of 2.6 (a ratio of 37.5:1 acrylamide/bisacrylamide), the concentration of glycerol $(10 \%)$ and the voltage $(500 \mathrm{~V})$ were kept constant for all sets.

The gels were silver stained and each patient presenting an abnormal pattern when compared with normal individuals was sequenced using Omnibase cycle sequencing kit (Promega, USA). The reactions were carried out as described by the manufacturer using $\alpha-{ }^{35} \mathrm{~S}$-dATP for labelling and analysed on $6 \%$ sequencing gel.

\section{Results}

In the framework of this work, 56 unrelated DMD/ BMD non-deletion patients were selected for the screening of point mutations in 18 exons of the dystrophin gene. A modified SSCA technique was established for the screening of point mutations in Turkish DMD/BMD patients.

Each patient was screened by SSCA analysis for point mutations within 18 exons of the dystrophin gene by using the sets A-I. Figure 1 shows the multiplex SSCA of a panel of individuals using set A comprising exons 19, 8 and 44 of the dystrophin gene. Different migration patterns were detected in four DMD patients in exons 19 and 8. Sequencing of exon 19 in patients 1 and 2 (lanes 2 and 5 respectively) revealed the presence of base substitutions, namely $2510 \mathrm{C}>\mathrm{T}$ and 2516

Table 1 Optimum conditions for each selected SSCP set. The $\mathrm{C} \%$ value (2.6), running buffer $(1 \times \mathrm{TAE})$, temperature $\left(20^{\circ} \mathrm{C}\right)$ and the voltage $(500 \mathrm{~V})$ were kept constant for each set

\begin{tabular}{lllll}
\hline Name & $\begin{array}{l}\text { Exon } \\
\text { numbers }\end{array}$ & $\begin{array}{l}\text { Product } \\
\text { sizes }(\mathrm{bp})\end{array}$ & $\begin{array}{l}\text { Gel conc } \\
(\%)^{\mathrm{a}}\end{array}$ & $\begin{array}{l}\text { Time } \\
(\mathrm{h})\end{array}$ \\
\hline A & $19,8,44$ & $459,360,268$ & 8 & 7 \\
$\mathrm{~B}$ & $17,12,13$ & $416,331,238$ & 8 & 7 \\
C & $3,50,60$ & $410,271,139$ & 8 & 8 \\
D & 51,6 & 388,202 & $8-10$ & 10 \\
E & 43,4 & 357,196 & 10 & 10 \\
F & 47,52 & 181,113 & 10 & 10 \\
G & 45 & 547 & $5-6$ & 6 \\
H & 48 & 506 & 6 & 6 \\
I & Pm & 535 & 6 & 6 \\
\hline
\end{tabular}

${ }^{a}$ Non-denaturing gels containing $10 \%$ glycerol $(\mathrm{C} \%=2.6)$. 


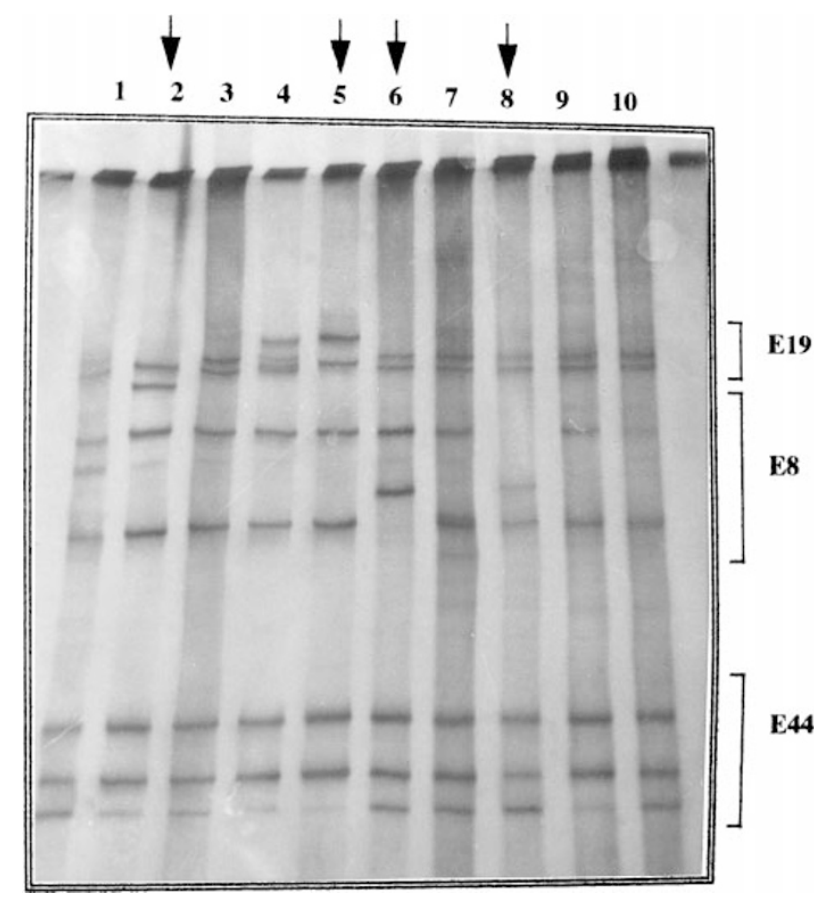

Figure 1 The SSCA of Turkish DMD/BMD patients by using set $A$ comprising exons 19, 8 and 44. Lanes 1 and 10: normal male controls, Lane 2: Patient 1, Lane 3: Mother of patient 1, Lane 4: Mother of patient 2, Lane 5: Patient 2, Lane 6: Patient 3, Lane 7: Patient 4, Lane 8: Patient 5, Lane 9: Patient 6. Big arrows indicate the patients with abnormal SSCA patterns for exon 19 and small arrows indicate the patients with abnormal SSCA patterns for exon 8.

A $>$ T, leading to the formation of stop signals at codons 768 (R768X) and 770 (K770X).

In order to identify their carrier status the mothers of both patients were also included in the SSCA. The presence of the same abnormally migrating band in addition to the normal one (lane 4) indicated that the mother of patient 2 was the carrier of the mutation. The SSCA showed the absence of the aberrant exon 19 band in the mother of patient 1 (lane 3 ). This observation suggested the non-carrier status of this mother. However, germline mosaicism could not be excluded for this mother.

Sequencing of exon 8 in patient 3 (lane 6) indicated the presence of a base substitution, $932 \mathrm{C}>\mathrm{T}$, which also creates a stop signal at codon 242 (Q242X). The sequence analysis of the same exon in patient 4 (lane 8) showed that the shift in the migration pattern was caused by a novel two basepair deletion (-CC) at position 980-981 (980-981delCC). This novel mutation causes a frameshift and creates a stop signal at codon 259 of exon 8 (P258-2X259) in this DMD patient.

SSCA analyses of Turkish DMD/BMD patients using set $\mathrm{D}$, comprising exons 51 and 6, displayed an abnormal pattern in exon 6 of a BMD patient. Sequence analysis of exon 6 in this patient showed the presence of a substitution, $\mathrm{G}$ to $\mathrm{C}$ at nucleotide position 719 (719G $>$ C), changing alanine to proline (A171P). This nucleotide variation, which was first described in the framework of this study, creates a restriction site for Mnl I enzyme. The mother and sister of this patient was also found to be carriers of this mutation (Figure 2).

The screening of 56 patients using sets B, E, $\mathrm{H}$ and I, comprising exons 17, 12 and 13; 43 and 52; 45 and 48, respectively, revealed the presence of six polymorphisms. The frequency of each polymorphism among the screened population of DMD/BMD patients was calculated either according to restriction enzyme analysis or from the direct observation of SSCA patterns. Mutations and polymorphisms identified in this study are summarised in Table 2.

\section{Discussion}

In one third of DMD/BMD cases the disease is caused by small mutations and since 1991, 203 different mutations have been reported to the DMD point mutation database so far.

In the present study $25.5 \%$ of the coding region of the dystrophin gene was screened using a modified multiplex SSCA. Mutations responsible for the disease

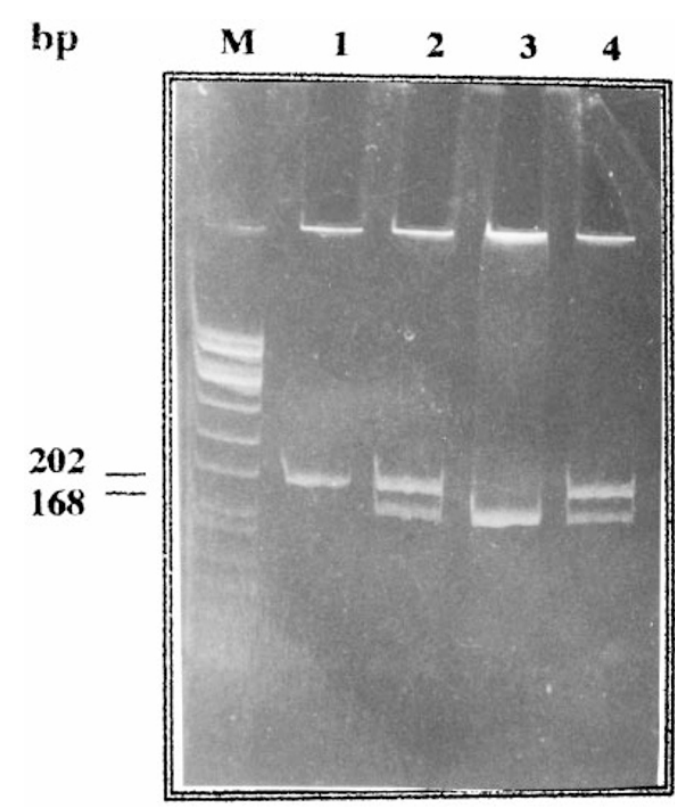

Figure 2 Mnl I digestion of exon 6 of the dystrophin gene. M: Marker DNA ( $\phi X 174 /$ Hinf I), Lane 1: Control DNA, Lane 2: Mother, Lane 3: Patient, Lane 4: Sister 
Table 2 Mutations and polymorphisms identified in Turkish DMD/BMD non-deletion patients using SSCA technique

\begin{tabular}{|c|c|c|c|c|c|c|}
\hline $\begin{array}{l}\text { Exon } \\
\text { No } 1\end{array}$ & Name & $R E$ site & $\begin{array}{l}\text { Effect on the } \\
\text { translation }\end{array}$ & Phenotype & $\begin{array}{l}\text { Observed } \\
\text { frequencies }\end{array}$ & References \\
\hline \multicolumn{7}{|c|}{ Mutations } \\
\hline 6 & $719 \mathrm{G}>\mathrm{C}$ & $+\mathrm{Mnl} \mathrm{I}$ & A $171 P$ & BMD & $0.02 \quad(1 / 56)$ & This study \\
\hline 8 & 980-981 del CC & - & P 258-2 X 259 & DMD & $0.02 \quad(1 / 56)$ & This study \\
\hline 8 & $932 \mathrm{C}>\mathrm{T}$ & - & $\mathrm{Q} 242 \mathrm{X}$ & DMD & $0.02 \quad(1 / 56)$ & $14-16$ \\
\hline 19 & $2510 \mathrm{C}>\mathrm{T}$ & - & R $768 X$ & DMD & $0.02 \quad(1 / 56)$ & $12,15,17$ \\
\hline 19 & $2516 \mathrm{~A}>\mathrm{T}$ & - & K $770 \mathrm{X}$ & DMD & $0.02 \quad(1 / 56)$ & 18 \\
\hline \multicolumn{7}{|c|}{ Polymorphisms } \\
\hline 13 & $1691-72 \mathrm{t} / \mathrm{c}$ & + Dde I & none & - & $0.21(12 / 56)$ & $5,19,20$ \\
\hline 13 & $1691-67 \mathrm{a} / \mathrm{t}$ & - & none & - & $0.04 \quad(2 / 56)$ & $5,19,20$ \\
\hline 17 & $2201-37$ & -Taq I & none & - & $0.45(25 / 56)$ & $5,11,12,14,19$ \\
\hline 43 & $6326-60 \mathrm{ins} / \mathrm{at}$ & - & none & - & $0.14 \quad(8 / 56)$ & 5 \\
\hline 45 & $6779 \mathrm{C} / \mathrm{T}$ & - & Arg 2191 Trp & - & $0.13 \quad(7 / 56)$ & 12,16 \\
\hline 48 & $7304 \mathrm{~A} / \mathrm{C}$ & -Mse I & Lys 2366 Gln & - & $0.50(28 / 56)$ & $7,19,21,22$ \\
\hline
\end{tabular}

phenotype could be identified in five out of 56 unrelated DMD/BMD patients included into this study. Two of these mutations are novel mutations which were not described previously.

Four among the five mutations detected in this study are found to cause the premature termination of the dystrophin synthesis and associated with the severe DMD phenotype as expected. $99.8 \%$ of point mutations reported so far leading to DMD phenotype were found to be nonsense mutations or frameshift mutations causing a premature termination of the dystrophin. The mutation $2510 \mathrm{C}>\mathrm{T}$ was already described in three DMD patients, 932C $>\mathrm{T}$ in one IMD and two DMD patients and 2516A $>\mathrm{T}$ in one DMD patient. The frameshift mutation, 980-981delCC, first described in this study was also identified in one DMD patient.

A novel missense mutation in exon 6 causing a substitution of alanine at position 171 with proline was described in a BMD patient. The identification of the sequence variation uniquely in the affected members and identified carriers of the family, and its absence in normal males and non-carrier females, indicated the possible role of this variation in the pathogenesis of the disease in this family. The amino acid alanine at position 171 of the dystrophin protein is highly conserved in the dystrophin of human, mouse and chicken. Furthermore investigation of the $\mathrm{NH}_{2}$ terminus actinbinding domains of the structurally related proteins showed the conservation of this residue in human utrophin, $\alpha$-actinin, $\beta$-spectrin, flamin and ABP-120 (Figure 3). These observations provided indirect evidence for the pathogenic nature of this variation.

Elucidation of the precise sequences required for the binding of F-actin is considered to be very important for the understanding of the pathogenesis of DMD and for the development of therapeutic approaches for this disease. It has been reported that dystrophin has been shown, in vitro, to have at least three actin binding sites, namely ABS 1-3, in the $\mathrm{NH}_{2}$ terminal actin-binding domain of this protein. ${ }^{24,25}$ However, the identification of a missense mutation in exon 3 of the dystrophin gene which does not reside in any of these binding sites

\begin{tabular}{cllllllllllllllllllll|l|lllll} 
dysH & 153 & Q & V & N & V & I & N & F & T & T & S & W & S & D & G & L & A & L & N & A & L & I & H & S & 175 \\
dysM & 153 & Q & V & N & V & I & N & F & T & S & S & W & S & D & G & L & A & L & N & A & L & I & H & S & 175 \\
dysC & 157 & Q & V & N & V & I & N & F & T & S & S & W & S & D & G & L & A & F & N & A & L & L & H & S & 179 \\
UtrH & 169 & Q & V & N & V & L & N & F & T & T & S & W & T & D & G & L & A & F & N & A & V & L & H & R & 192 \\
SPCB & 192 & H & V & N & V & T & N & F & T & S & S & W & K & D & G & L & A & F & N & A & L & I & H & K & 216 \\
AAC3 & 177 & N & V & N & V & Q & N & F & H & T & S & W & K & D & G & L & A & L & C & A & L & I & H & R & 201 \\
ABP120 & 143 & K & V & V & V & N & N & F & T & D & S & W & C & D & G & R & V & L & S & A & L & T & D & S & 165 \\
filH & 155 & Q & L & P & I & T & N & F & N & R & D & W & Q & D & G & K & A & L & G & A & L & V & & & 175
\end{tabular}

Figure 3 Alignments of the partial amino acid sequence of dystrophins and $\mathrm{NH}_{2}$ terminus actin-binding domains of the structurally related proteins; human dystrophin (dysH); mouse dystrophin (dysM); chicken dystrophin (dysC); human utrophin (utrH); human beta spectrin (SPCB); human alpha actinin-skeletal muscle isoform (AAC3); actin-binding protein 120 (ABP120); human filamin (filH). The sequences were aligned with the aid of a protein database similarity search program, PSI-BLAST. ${ }^{23}$ 
suggested that amino acid 54 may also be important for the function of the protein possibly due to interaction with actin. ${ }^{26}$ The missense mutation identified in the present study, resulting in a substitution of alanine for a proline at position 171 which does not reside in any of these three actin-binding sites indicated the importance of this residue possibly in the actin binding function of the protein.

The fact that this missense mutation is associated with the BMD phenotype indicates that this mutation may only reduce the stability or the function of the protein. Further studies are required to clarify the effect of $719 \mathrm{G}>\mathrm{C}$ on the biological function and the severity of the mutation. However, it should be kept in mind that other genetic factors may also be important in the creation of a milder phenotype in this patient.

A mutation detection rate of $9.6 \%$ was observed as expected in this study by the analysis of almost one fourth of the coding region of the dystrophin gene in the present study. The non-radioactive multiplex SSCA system optimised for screening 18 exons seems to be a sensitive and reproducible approach for the rapid screening of pathological mutations. The design and optimisation of the multiplex systems to screen other exons of the dystrophin gene needs to be established and further studies using these systems will possibly reveal other mutations responsible for the $\mathrm{DMD} / \mathrm{BMD}$ phenotype.

\section{Acknowledgements}

This study was supported partly by TUBITAK/TBAG (Turkish Scientific Research Council) 1160, TTGV (Technology Development Foundation of Turkey) 086 and Boğaziçi University Research Fund 93BO116 projects.

\section{References}

1 Scriver CR, Beaudet AL, Sly WS, Valle D: Metabolic and Molecular Basis of Inherited Disease, 7th edn. McGraw Hill International (UK), 1997, pp 4199.

2 Beggs AH, Koenig M, Boyce FM, Kunkel LM: Detection of 98-percent DMD/BMD gene deletions by polymerase chain reaction. Hum Genet 1990; 86(1): 45-48.

3 Gibbs RA, Chamberlain JS, Caskey CT: Diagnosis of new mutation diseases using a polymerase chain reaction. In: Erlich HA (ed.). PCR Technology: Principles and Applications for DNA Amplification. Stockton Press: New York, 1989, pp 71-191.

$4 \mathrm{Hu}$ XY, Burghes AH, Ray PN, Thompson MW, Murphy EG, Worton RG: Partial gene duplications in Duchenne and Becker muscular dystrophies. J Med Genet 1988; 25(6): 369-376.
5 Leiden Muscular Dystrophy website http://www.dmd.nl; Muscular dystrophy (point) mutation databases (/dys_ mutat.html)

6 Bulman DE, Gangopadhyay SB, Bebchuck KG, Worton RG, Ray PN: Point mutation in the human dystrophin gene: Identification through western blot analysis. Genomics 1991; 10(2): 457-460.

7 Kilimann MW, Pizzuti A, Grompe M, Caskey CT: Point mutation and polymorphisms in the human dystrophin gene identified in genomic DNA sequences amplified by multiplex PCR. Hum Genet 1992; 89(3): 253-258.

8 Roest PA, Bout M, Van Der Tuijn AC et al: Splicing mutations in DMD/BMD detected by RT-PCR/PTT: detection of a 19AA insertion in the cysteine-rich domain of dystrophin compatible with BMD. J Med Genet 1996; 33(11): 935-939.

9 Saad FA, Vita G, Toffolatti L, Danieli GA: A possible missense mutation detected in the dystrophin gene by double strand conformation analysis (DSCA). Neuromusc Disord 1994; 4(4): 335-341.

10 Prior TW, Wenger GD, Papp AC et al: Rapid DNA haplotyping using a multiplex heteroduplex approach: Application to Duchenne muscular dystrophy carrier testing. Hum Mutat 1995; 5(3): 263-268.

11 Nigro V, Politano L, Nigro G, Romano SC, Molinari AM, Puca GA: Detection of a nonsense mutation in the dystrophin gene by multiplex SSCA. Hum Mol Genet 1992; 1(7): 517-520.

12 Kneppers AL, Deutz-Terlouw PP, Den Dunnen JT, Van Ommen GJB, Bakker E: Point mutation screening for 16 exons of the dystrophin gene by multiplex single-strand conformation analysis (SSCA) analysis. Hum Mutat 1995; 5(3): 235-242.

13 Sitnik R, Campiotto S, Vainzof M et al: Novel point mutations in the dystrophin gene. Hum Mutat 1997; 10(3): 217-222.

14 Prior TW, Papp AC, Snyder PJ et al: Heteroduplex analysis of the dystrophin gene: application to point mutation and carrier detection. Am J Med Genet 1994; 50(1): 68-73.

15 Akalin N, Zietkiewicz E, Makalowski W, Labuda D: Are $\mathrm{CpG}$ sites mutation hot spots in the dystrophin gene. Hum Mol Genet 1994; 3(8): 1425-1426.

16 Nigro V, Nigro G, Esposito MG et al: Novel small mutations along the DMD/BMD gene associated with different phenotypes. Hum Mol Genet 1994; 3(10): 1907-1908.

17 Prior TW, Papp AC, Snyder PJ et al: Identification of two point mutations and a one base deletion in exon 19 of the dystrophin gene by heteroduplex formation. Hum Mol Genet 1993; 2(3): 311-313.

18 Roberts RG, Gardner RJ, Bobrow M: Searching for the 1 in 2,400,000: a review of dystrophin gene point mutations. Hum Mutat 1994; 4(1): 1-11.

19 Tuffery S, Moine P, Demaille J, Claustres M: Base substitutions in the human dystrophin gene: detection by using the single-strand conformation analysis (SSCA) technique. Hum Mutat 1993; 2(5): 368-374.

20 Lenk U, Hanke R, Kraft U, Grade K, Grunewald I, Speer A: Non-isotopic analysis of single strand conformation analysis (SSCA) in the exon 13 region of the human dystrophin gene. J Med Genet 1993; 30(11): 951-954. 
21 Roberts RG, Bobrow M, Bentley DR: Point mutations in the dystrophin gene. Proc Natl Acad Sci USA 1992; 89(6): 2331-2335.

22 Yau SC, Roberts RG, Bentley DR et al: A MseI polymorphism in exon 48 of the dystrophin gene. Nucleic Acids Res 1991; 19(20): 5803.

23 Stephen F, Madden TL, Schaffer AA et al: Gapped BLAST and PSI-BLAST: a new generation of protein database search programs. Nucleic Acids Res 1997; 25: 3389-3402.
24 Corrado K, Mills PL, Chamberlain JS: Deletion analysis of the dystrophin-actin binding domain. FEBS Letters 1994; 344: 255-260.

25 Jarett HW, Foster JL: Alternate binding of actin and calmodulin to multiple sites on dystrophin. J Biol Chem 1995; 270(10): 5578-5586.

26 Prior TW, Papp AC, Snyder PJ: A missense mutation in the dystrophin gene in a Duchenne muscular dystrophy patient. Nat Genet 1993; 4: 357-360. 